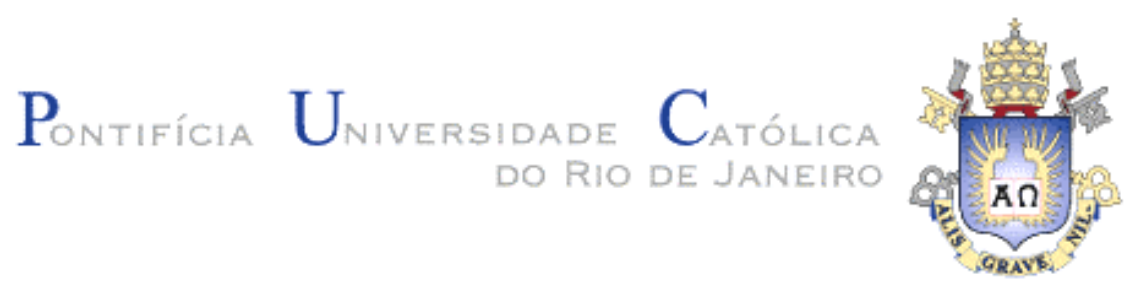

Matilde Villela de Souza

Transporte eletrocinético de gasolina e óleo através de um solo residual gnáissico e borra de petróleo da Bacia de Campos

Dissertação de Mestrado

Dissertação apresentada como requisito parcial para obtenção do grau de Mestre pelo Programa de Pós-graduação em Engenharia Civil do Departamento de Engenharia Civil da PUCRio. Área de concentração: Geotecnia.

Orientador: Prof. José Tavares Araruna Júnior 


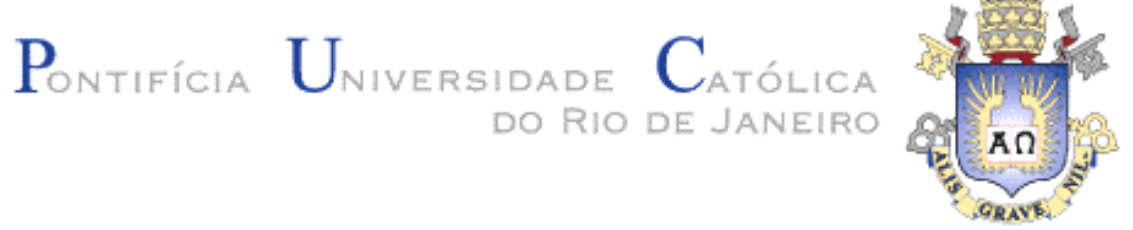

Matilde Villela de Souza

\section{Transporte eletrocinético de gasolina e óleo através de um solo residual gnáissico e borra de petróleo da Bacia de Campos}

Dissertação apresentada como requisito parcial para obtenção do grau de Mestre pelo Programa de Pós-graduação em Engenharia Civil do Departamento de Engenharia Civil do Centro Técnico Científico da PUC-Rio. Aprovada pela Comissão Examinadora abaixo assinada.

Prof. José Tavares Araruna Júnior

Orientador

Departamento de Engenharia Civil - PUC-Rio

Prof. Eurípedes do Amaral Vargas Jr. Departamento de Engenharia Civil - PUC-Rio

Prof. Izabel Christina d'Almeida Duarte de Azevedo Universidade Federal de Viçosa

Prof. Sérgio Tibana Universidade Estadual do Norte Fluminense

Prof. Ney Augusto Dumont Coordenador Setorial do Centro Técnico Científico - PUC-Rio

Rio de Janeiro, 04 de Outubro de 2002 
Todos os direitos reservados. É proibida a reprodução total ou parcial do trabalho sem autorização da universidade, da autora e do orientador.

\section{Matilde Villela de Souza}

Graduou-se em Engenharia Civil com ênfase Ambiental na PUC-Rio (Pontifícia Universidade Católica do Rio de Janeiro) em 2000. Desenvolveu junto com essa Universidade, projetos de Iniciação Científica com bambu, como um material de construção não convencional para a construção civil, incluindo a produção de trabalhos inovadores na área. Trabalha na Assessoria de Segurança e Meio Ambiente de uma Empresa privada.

Ficha Catalográfica

Souza, Matilde Villela de

Transporte eletrocinético de gasolina e óleo através de um solo residual gnáissico e borra de petróleo da Bacia de Campos / Matilde Villela de Souza ; orientador: José Tavares Araruna Júnior. - Rio de Janeiro : PUC, Departamento de Engenharia Civil, 2002.

[19], 137 f. : il. ; $30 \mathrm{~cm}$

Dissertação (mestrado) - Pontifícia Universidade Católica do Rio de Janeiro, Departamento de Engenharia Civil.

Inclui referências bibliográficas.

1. Engenharia civil - Teses. 2. Eletrocinese. 3. Descontaminação. 4. Solo residual. 5. Gasolina. 6. Óleo cru. 7. Borra de petróleo. I. Araruna Júnior, José Tavares. II. Pontifícia Universidade Católica do Rio de Janeiro. Departamento de Engenharia Civil. III. Título. 
À minha mãe e ao meu pai, amigos eternos,

Muito amor, sempre.

E ao meu padrinho, saudades. 


\section{Agradecimentos}

À minha família, pai, mãe, Lela, Lila, vó e vô, pelo eterno apoio, confiança e dedicação. Pelas conversas, pelo colo, pelo incentivo, credibilidade e acima de tudo pelo carinho e amor sempre tão necessários e preciosos. Muito obrigada, vocês são tudo de mais especial na minha vida.

Ao João, pelos maravilhosos momentos, pelo incentivo em fases difíceis, pelo companheirismo, pela concepção trabalho, por estar do meu lado, e claro, pela boa música. Muito obrigada, e muito amor. Também à sua família, que considero um pouco minha...

A todos meus amigos e companheiros de pós-graduação, pelo estudo, pelas madrugadas, conversas, trocas, pelos momentos de euforia e de angústia, Muito obrigada, já com saudades. Em especial à Flávia e à Ana Júlia, queridas companheiras.

Aos meus amigos extra estudo, por simplesmente serem meus amigos, sempre.

Ao meu orientador, José Araruna, pelo seu apoio, sua tranqüilidade, disponibilidade, informalidade e pelo seu empenho em momentos complicados. Muito obrigada. 
A todos meus professores de graduação e de pós-graduação da PUC-Rio que tanto me ensinaram. Em especial ao mestre Franklin, com todo seu carinho, apoio e perfeição didática.

A todos da secretaria, Ana, Fátima, Cristiano e Lenilson (quanto tempo), pelos sorrisos, empenho e boa vontade.

Ao pessoal do Laboratório de Geotecnia da PUC-Rio: Sr. José, pelas suas palavras, pela sua arte, dedicação e por ser tão prestativo. Ao mestre William, também pela sua dedicação, pelos seus ensinamentos e boa vontade. Ao Josué e Amaury, pela constante ajuda, e pelos momentos essenciais de descontração. Muito obrigada de coração por todos esse tempo que compartilhei com vocês, certamente será eterno na minha vida.

Ao pessoal da xerox da Engenharia da Vila dos Diretórios, em especial ao Valter e ao Mineiro, pelos anos de convívio, ajuda e carinho.

Ao pessoal do Laboratório de Química, Rodrigo e André, pela ajuda, boa vontade, pelo tempo desprendido e por serem tão prestativos.

Ao pessoal do Departamento de Engenharia dos Materiais, professor Raul, Marcos e Glória, pela tentativa desesperada de adquirir resultados quando tudo parecia perdido.

Às biólogas Denise e Patrícia, pelo uso do Laboratório de Biologia em algumas análises químicas, cujos odores eram bastante incovenientes, pela ajuda, boa vontade e companhia.

Ao amigo Flávio, pelos ensinamentos computacionais e pela extrema boa vontade. Também ao Daniel e André, amigos atuais de trabalho.

À querida Eutália, pela sua ajuda tão carinhosa no Abstract, dentre outras, claro 
Ao amigo Alexandre, Químico, pela ajuda em diversas análises e pelas conversas, cafés e momentos descontraídos. E claro, pela maravilhosa comida paraense.

À CAPES, à ANP e à PUC-Rio, pelos auxílios concedidos, sem os quais este trabalho não poderia ter sido realizado.

A todos que participaram nesta fase da minha vida.

Existem momentos preciosos que muitas vezes não são percebidos, mas sei o quão foram importantes quando paro para pensar nessas pessoas que de alguma forma estão guardadas para sempre no meu coração.

Mais uma vez, muito obrigada. 


\section{Resumo}

Souza, Matilde Villela; Araruna, José Tavares Júnior. Transporte eletrocinético de gasolina e óleo através de um solo residual gnáissico e borra de petróleo da Bacia de Campos. Rio de Janeiro, 2002. Dissertação de Mestrado - Departamento de Engenharia Civil, Pontifícia Universidade Católica do Rio de Janeiro.

O transporte eletrocinético de gasolina e óleo através de um solo residual gnáissico é focado na utilização da eletrocinese como uma técnica de remediação para solos finos. Baseia-se na aplicação de uma diferença de potencial através de uma massa de solo, com a conseqüente produção de um fluxo eletrocinético, o qual envolve mecanismos como eletroosmose (fluxo de água) e migração de íons.

$\mathrm{Na}$ primeira etapa, amostras de solo foram contaminadas com gasolina e com óleo cru. Os ensaios mostraram que a presença desses compostos não variou o comportamento dos parâmetros eletroosmóticos, assim como o pH e a condutividade elétrica dos eletrólitos e do próprio solo. Em dois dos ensaios realizados com óleo, observou-se um notório transporte em direção ao anodo devido à eletroosmose. Já com a gasolina os resultados das determinações analíticas sugeriram o transporte da mesma, embora que em uma escala reduzida.

$\mathrm{Na}$ segunda etapa analisou-se a remediação dos metais e do óleo presentes em uma borra de petróleo da Bacia de Campos, para a utilização desta como material geotécnico. Nenhum teor significativo de metal foi encontrado na borra antes do ensaio, em contrapartida, observou-se contaminação de zinco pela corrosão dos eletrodos de latão utilizados. E quanto ao óleo, notou-se um transporte considerável devido à eletroosmose.

\section{Palavras chave}

Eletrocinese - Eletrólise - Eletrodos - Remediação -Gasolina - Óleo cru - Borra de petróleo - Metais - Corrosão 


\section{Abstract}

Souza, Matilde Villela; Araruna, José Tavares Júnior (Advisor). Electrokinetic transport of gasoline and oil through a gnaissic residual soil and oil gound from Campos Basin. Rio de Janeiro, 2002. MSc. Dissertation - Departamento de Engenharia Civil, Pontifícia Universidade Católica do Rio de Janeiro.

This study assesses the use of electrokinetics as an innovative technique for remediation of fine-grained soils. It relies on the application of an electrical potential through a soil mass, producing a series of coupled flows, including fluid flow (electroosmosis) and migration of ions.

The first stage of the experimental program encompassed a series of tests with samples of residual soil contaminated with gasoline and crude oil. The results showed that the presence of these compounds did not affect the electroosmotic behavior, and there was observed no changes on the $\mathrm{pH}$ and electric conductivity of neither the electrolytes solution nor the soil itself.

When oil contaminated samples are of concern, it was noticed a clear electroosmotic flow towards the anode. This pattern was also observed, but at a reduced level, on the tests on the gasoline contaminated samples.

The second stage of the experimental program consisted on a series of tests with oil ground from Campos Basin aiming on dewatering and de-oiling. The results were satisfying, in all sample there was a noticeable reduction on the water and oil contents. Tests results also showed a zinc contamination on the sample caused by electrolysis on the brass electrodes.

\section{Keywords}

Electrokinetic - Eletrolise - Eletrode - Remediation - Gasoline - Crude oil

Petroleum waste - Metals - Corrosion 


\section{Sumário}

$\begin{array}{ll}\text { 1. Introdução } & 20\end{array}$

2. Abordagem Teórica 24

2.1. Princípios da Eletrocinese 25

2.1.1. Sistema Solo-Água 25

2.1.2. Teorias sobre a Camada Dupla Elétrica 27

2.1.3. Eletrocinese em Solos e o Potencial Zeta 31

2.1.4. Efeito da Eletrocinese nos Solos 42

2.2. Remediação de Solos Finos pela Eletrocinese 48

3. Aspectos Experimentais 56

3.1. Descrição do solo 56

3.1.1. Ensaios de Caracterização 56

3.1.2. Ensaios Químicos 58

3.1.3. Ensaios de permeabilidade 60

3.1.4. Ensaios de Mineralogia 62

3.2. Descrição da Borra de Petróleo 63

3.3. Descrição das Células $\quad 64$

3.3.1. Célula $1 \quad 64$

$\begin{array}{ll}\text { 3.3.2. Célula } 2 & 67\end{array}$

3.4. Procedimento de ensaios 68

3.4.1. Célula 1 - Avaliação da Eletrocinese 68

3.4.2. Célula 1 - Ensaios com Contaminante (gasolina e óleo) 73

3.4.3. Extração de Compostos Orgânicos

3.4.3.1. Extração propriamente dita $\quad 74$

3.4.3.2. INFRACAL TOG/TPH 77

3.4.3.3. Calibração do Infracal TOG/TPH 79

3.4.3.4. Fluorescência 80

3.4.4. Célula $2 \quad 81$

3.4.4.1. Lixiviação (Análise dos Metais) 83

3.4.4.2. Extração de óleo 85

4. Apresentação e Discussão dos Resultados 86 
4.1. Eletrocinese em solo não contaminado 86

4.1.1. Fluxo reverso $\quad 86$

4.1.2. Índices Físicos Iniciai $\quad 87$

4.1.3. Parâmetros Eletroosmótico 88

4.1.3.1. Vazão 88

4.1.3.2. Coeficiente de permeabilidade eletrosmótico (ke) 90

$\begin{array}{ll}\text { 4.1.3.3. Corrente } & 91\end{array}$

4.1.3.4. Constante de Eficiência Eletroosmótica (ki) 92

4.1.3.5. $\mathrm{pH} \quad 94$

4.1.4. Índices Físicos Finais 95

4.2. Eletrocinese no solo contaminado com Gasolina 97

4.2.1. Índices Físicos Iniciais 98

4.2.2. Parâmetros Eletroosmóticos 99

4.2.2.1. Vazão 99

4.2.2.2. Coeficiente de permeabilidade eletrosmótico (ke) 100

$\begin{array}{ll}\text { 4.2.2.3. Corrente } & 101\end{array}$

4.2.2.4. Coeficiente de Eficiência Eletroosmótica, ki 102

4.2.2.5. $\mathrm{pH} \quad 103$

4.2.2.6. Condutividade Elétrica 105

4.2.3. Índices Físicos Finais 107

4.2.4. Análises da descontaminação 108

4.2.4.1. Fluorescência 108

4.2.4.2. Análise deBTEX 110

4.3. Eletrocinese de solos contaminados com óleo 112

4.3.1. Índices físicos Iniciais 113

4.3.2. Parâmetros eletroosmóticos 113

4.3.2.1. Vazão 113

4.3.2.2. Coeficiente de Permeabilidade eletroosmótica, ke 114

$\begin{array}{ll}\text { 4.3.2.3. Corrente } & 115\end{array}$

4.3.2.4. Coeficiente de eficiência eletroosmótica, ki 116

4.3.2.5. $\mathrm{pH} \quad 117$

4.3.2.6. Condutividade Elétrica 119

4.3.3. Índices físicos finais 120

4.3.4. Avaliação da Remediação Eletrocinética 122

4.3.4.1. Extrações de óleo do solo 122

4.4. Eletrocinese na Borra de Petróleo 124

4.4.1. Peso Específico 124

4.4.2. Parâmetro eletroosmótico 124

4.4.2.1. Corrente 125

4.4.3. Resultados da Remediação da Borra 126

4.4.3.1. Transporte de íons Análise por Lixiviação (NBR 10005) EK1 126

4.4.3.2. Transporte de óleo - EK2 129 
5. Conclusões e Sugestões

6. Revisão Bibliográfica 


\section{Lista de Figuras}

Figura 1.1 - Tanque de gasolina subterrâneo 20

Figura 1.2 - Vazamento em uma tubulação 21

Figura 1.3 - Vazamento em um tanque de gasolina 21

Figura 2.1 - Esquema de instalação em campo para remediação in situ pelo fluxo eletroosmótico (Shapiro \& Probstein, 1993) 24

Figura 2.2 - Distribuição de íons adjacentes a uma superfície de argila (Mitchell, 1993)

Figura 2.3 - Efeito do pH na Carga de superfície da Montmorilonita e da Caulinita (Alshawabkeh, 2001)

Figura 2.4 - O campo elétrico num capacitor de pratos paralelos. (a) $\mathrm{O}$ dieletro é um vácuo. (b) É apresentado o material do dieletro constante, er. (Hiemenz, 1986)

28

Figura 2.5 - Dois modelos para a camada dupla difusa: (a) a camada dupla difusa e (b) neutralização de carga devido parcialmente à distribuição de carga de uma prato paralelo e parcialmente à camada difusa (Hiemenz, 1986)

Figura 2.6 - Eletroforese (Mitchell, 1993) 32

Figura 2.7 - Eletroosmose (Mitchell, 1993) 33

Figura 2.8 - Potencial de fluxo (Mitchell, 1993) 33

Figura 2.9 - Migração ou Potencial de Sedimentação (Mitchell, 1993)

Figura 2.10 - Ilustração do esquema da variação do potencial com a distância de uma parede carregada na presença da camada de Stern. Significado dos subscritos: 0 na parede; d na superfície de Stern; d na camada difusa (Hiemenz, 1986)

Figura 2.11 - Linhas de Fluxo (que também representam o campo elétrico) ao redor de partículas esféricas de raio $R$. As linhas tracejadas representam a espessura da camada dupla, K-1. Em (a) KR é pequeno; em (b) KR é grande. (Hiemenz, 1986)

Figura 2.12 - As magnitudes relativas de vários potenciais da camada dupla (Hiemenz, 1986)

Figura 2.13 - Situação de um elemento de um volume de uma solução adjacente à uma parede planar. (Hiemenz, 1986)

Figura 2. 14 - Migração através do solo sob um campo elétrico descrevendo a geração e o transporte de produtos da eletrólise da água (íons $\mathrm{H}_{+} / \mathrm{OH}-$ ) e a reação de auto-ionização da água perto do catodo. (Acar et al. 1995) 
Figura 2.15 - A razão da mobilidade iônica, $\mathrm{u}^{*}$, do $\mathrm{H}+, \mathrm{OH}-, \mathrm{Pb} 2+\mathrm{e}$ CO2/3- com o coeficiente de permeabilidade eletroosmótica, ke, versos o coeficiente de permeabilidade eletroosmótica.(Acar et al., 1995)

Figura 2.16 - Degradação de um anel benzênico. (a) Degradação aeróbica do benzeno na presença de oxigênio. (b) Degradação anaeróbica do fenol na presença de nitrato. (Fetter, 1992)

Figura 3.1 - Curva Granulométrica do solo do município de Duque de Caxias (RJ)

Figura3.2 - Antes do reagente

Figura 3.3 - Depois do reagente

Figura 3.4 - Ensaio de permeabilidade

Figura 3.5 - Difractograma do solo de Duque de Caxias - RJ (Nunes, 2002)

Figura 3.6 - Célula 1 de Eletrocinese 64

Figura 3.7 - Vista superior da parte central da célula 1

Figura 3.8 - Extremidades da célula 1 acopladas com a parte central $\quad 66$

Figura 3.9 - Eletrodos sendo fixados na extremidade da célula $1 \quad 66$

Figura 3.10 - Montagem da célula $1 \quad 67$

Figura 3.11 - Célula $2 \quad 68$

Figura 3.12 - Homogeneização da amostra 69

Figura 3.13 - Retirada de vazios do solo $\quad 70$

Figura 3.14 - Auxílio de um acoplador $\quad 70$

Figura 3.15 - Vista superior da célula com acoplador 70

Figura 3.16 - Primeiro estágio de compactação $\quad 71$

Figura 3.17 - Arranjo do ensaio de Eletrocinese 72

Figura 3.18 - Amostras no shaker 76

Figura 3.19 - Erlenmeyres com solo e PCE 76

Figura 3.20 - Filtração dos extratos 77

Figura 3.21 - Aferição dos balões volumétricos 77

Figura 3.22 - Equipamento de medição de hidrocarbonetos totais 77

Figura 3.23 - A medição da absorção IR de uma amostra de óleo em uma cubeta de quartzo 79

Figura 3.24 - Gráfico Absorbância x Concentração 79

Figura 3.25 - Fluorímetro $\quad 81$

Figura 3.26 - Célula 2 dividida em 8 fatias 82

Figura 3.27 - Célula 2 dividida em 4 fatias 83

Figura 3.28 - Amostras da lixiviação no shaker 84

Figura 3.29 - Vista superior da lixiviação $\quad 84$

Figura 3.30 - Filtração à vácuo das amostras lixiviadas 84

Figura 3.31 - Amostras filtradas para análise no ICP 85

Figura 3.32 - ICP $\quad 85$

Figura 3.33 - Close do ICP 85

Figura 4.1 - Vazão $x$ tempo para os ensaios de Eletrocinese sem contaminação 
Figura 4.2 - Vazio numa amostra de solo depios da compactação

Figura 4.3 - Gráfico: Coeficiente de permeabilidade $x$ tempo para os ensaios de Eletrocinese sem contaminação

Figura 4.4 - Gráfico: Corrente x tempo para os ensaios sem contaminação

Figura 4.5 - Gráfico: Coeficiente de Eficiência Eletroosmótica $x$ tempo para ensaios de Eletrocinese sem contaminação

Figura 4.6 - Gráfico pH da água dos compartimentos $x$ tempo para ensaios de Eletrocinese sem contaminação

Figura 4.7 - Variação do pH no solo em 3 diferentes estágios, após o término dos mesmos

Figura 4.8 - Variação da umidade ao longo da célula para os ensaios de Eletrocinese sem contaminação

Figura 4.9 - Visualização do fluxo eletroosmótico em um ensaio com solo contaminado por gasolina

Figura 4.10 - Gráfico Vazão x tempo para ensaios de Eletrtocinese em solos contaminados com gasolina 100

Figura 4.11 - Gráfico coeficiente de permeabilidade eletrosmótica x tempo para um solo contaminado com gasolina 101

Figura 4.12 - Gráfico: Corrente x tempo para solos contaminados com gasolina

Figura 4.13 - Gráfico coeficiente de eficiência eletroosmótica x tempo para solos contaminados com gasolina 103

Figura 4.14 - Gráfico: pH dos compartimentos x tempo para ensaios contaminados com gasolina 104

Figura 4.15 - Variação do pH de solos contaminados com gasolina 104

Figura 4.16 - Gráfico condutividade dos compartimentos $\mathrm{x}$ tempo para solos contaminados com gasolina

105

Figura 4.17 - Variação da condutividade do solo em ensaios contaminados com Gasolina 106

Figura 4.18 - Variação da Umidade relativa nos solos contaminados com gasolina

108

Figura 4.19 - Análise qualitativa da água percolada através do fluorímetro 109

Figura 4.20 - Transporte dos BTEXs numa amostra de solo contaminado com gasolina

Figura 4.21 - Transporte do Total de BTEXs para uma amostra de solo contaminado com gasolina

Figura 4.22 - Gráfico vazão x tempo para ensaios de solos contaminados com óleo

Figura 4.23 - Gráfico coeficiente de permeabilidade eletroosmótica $x$ tempo para solos contaminados com óleo

Figura 4.24 - Gráfico corrente x tempo para solos contaminados com óleo

Figura 4.25 - Gráfico coeficiente de eficiência eletroosmótica x tempo para solos contaminados com óleo 
Figura 4.26 - Gráfico pH dos compartimentos $\mathrm{x}$ tempo para solos contaminados com óleo 118

Figura 4.27 - Variação do pH nos solos contaminados com óleo, antes e depois dos ensaios

Figura 4.28 - Gráfico condutividade x tempo da água dos compartimentos de amostras contaminadas com óleo

Figura 4.29 - Gráfico da variação da condutividade do solo contaminado com óleo antes e depois dos ensaios

Figura 4.30 - Variação da umidade relativa ao longo de amostras de solo contaminados com óleo

121

Figura 4.31 - Transporte de óleo no ensaio EK1 122

Figura 4.32 - Transporte de óleo no ensaio EK3 123

Figura 4.33 - Volume percolado nos ensaios com a borra de petróleo

Figura 4.34 - Gráfico Corrente x tempo para os ensaios realizados com a borra do petróleo 126

Figura 4.35 Eletrodo de latão após aproximadamente 24 hs de ensaio

Figura 4.36 - Eletrodo de latão após 3 dias de ensaio 128

Figura 4.37 - Eletrodo de latão após aproximadamente 1 semana de ensaio

Figura 4.38 - Eletrodo de latão após mais de uma semana de ensaio

Figura 4.39 - Migração do zinco introduzido pela corrosão dos eletrodos de latão na Borra de Petróleo

129

Figura 4.40 - Transporte de óleo na Borra de Petróleo

130 


\section{Lista de Tabelas}

Tabela 3.1 - Resumo da Granulometria 57

Tabela 3.2 - Limites de Consistência 57

Tabela 3.3 - Valores medidos de pH 58

Tabela 3.4 - Conteúdo de matéria orgânica em 3 amostras do solo de Duque de Caxias (RJ)

Tabela 3.5 - Complexos intercambiáveis do solo (meq/100g de solo seco)

60

Tabela 3.6 - Valores de permeabilidade hidráulica para diferentes tensões e índices de vazios

Tabela 3.7 - Composição da borra de Petróleo (Exploração e Produção da borra da Bacia de Campos (E\&P ASSEMA) 63

Tabela 3.8 - Medidas da parte central da célula $1 \quad 64$

Tabela 3.9 - Medidas das extremidades da parte central 65

Tabela 3.10 - Medidas da célula $\quad 67$

Tabela 3.11 - Estágios de Compactação 70

Tabela 4.1 - Índices Físicos iniciais das amostras de solo não contaminado

87

Tabela 4.2 - Índices Físicos Finais de amostras de solo não contaminados

97

Tabela 4.3 - Índices Físicos iniciais de amostras contaminadas com gasolina

Tabela 4.4 - Tempo de duração correspondente a cada ensaio 106

Tabela 4.5-Índices Físicos Finais para Amostras de solo com gasolina

Tabela 4.6 - Comparação do volume percolado para alguns ensaios eletrocinéticos 110

Tabela 4.7 - Propriedades dos BTEX (Newell et al.,EPA 1995) 111

Tabela 4.8 - Propriedades do óleo 112

Tabela 4.9 - Índices Físicos Iniciais para amostras de solo contaminadas com óleo

113

Tabela 4.10 - Índices físicos finais de amostras de solo contaminadas com óleo

Tabela 4.11 - Concentração (em ppm) dos metais na Borra de Petróleo, segundo análises por Lixiviação 


\section{Lista de Símbolos}

E: resistência ao campo elétrico

$\psi:$ potencial Elético

$\rho^{*}$ : densidade de massa

$\varepsilon_{\mathrm{r}}$ : fator de proporcionalidade ente o campo elétrico o número de linhas de força

$\varepsilon_{0}$ : constante dielétrica do meio

$\mathrm{n}_{\mathrm{i}}$ : número de íons i por unidade de volume

z: valência do íon

e: carga do elétron

$\mathrm{T}$ : temperatura

$\mathrm{K}^{-1}$ : espessura da camada dupla

$\delta$ : distância da camada de Stern à superfície da partícula

$\mathrm{F}_{\mathrm{el}}$ : força elétrica

q: carga do íon

$\mathrm{F}_{\text {vis }}$ : força viscosa

$f$ : fator de fricção

v: velocidade do íon

$\mathrm{R}$ : raio de uma partícula ou íon

$\eta$ : viscosidade do líquido da solução

$\mu$ : mobilidade de um íon

A: área da partícula

$\zeta:$ potencial zeta

I: corrente elétrica

$\mathrm{k}$ : condutividade elétrica

$\mathrm{V}$ : voltagem

$\mathrm{H}_{2} \mathrm{O}$ : molécula de água

$\mathrm{O}_{2}$ : átomo de oxigênio

$\mathrm{H}^{+}$: íon hidrogênio

$\mathrm{H}_{2}$ : átomo de hidrogênio

$\mathrm{OH}$ : íon hidróxido

$\mathrm{E}_{0}$ : potencial de oxidação-redução

$\mathrm{k}_{\mathrm{e}}$ : coeficiente de permeabilidade eletroosmótica 
n: porosidade do meio sólido

F: fluxo de massa

$\mathrm{D}_{\mathrm{d}}$ : coeficiente de difusão

C: concentração da solução

D*: coeficiente de difusão efetivo

w: tortuosidade do emio poroso

$\mathrm{k}_{\mathrm{h}}$ : coeficiente de permeabilidade hidráulica

$\mathrm{i}_{\mathrm{h}}$ : gradiente hidráulico

h: carga hidráulica

1: comprimento da amostra

D: coeficiente de dispersão hidrodinâmica

$\alpha$ : dispersividade dinâmica

$\mathrm{K}_{\mathrm{ow}}$ : coeficiente de partição octanol-água

$\mathrm{K}_{\mathrm{p}}$ : coeficiente de sorção

$\mathrm{K}_{\mathrm{oc}}$ : coeficiente de sorção normalizada de carbono

S: massa sorvida

$\mathrm{P}_{\mathrm{u}}$ : consumo de energia por unidade de volume

$\mathrm{I}_{\sigma}$ : densidade de corrente

$\mathrm{K}_{\mathrm{a}}$ : condutividade aparente

$\mathrm{i}_{\mathrm{e}}$ : gradiente elétrico

$\mathrm{KCl}$ : cloreto de potássio

$\mathrm{CaCl}_{2}$ : cloreto de cálcio

MO: conteúdo de matéria orgânica

$\mathrm{C}_{\mathrm{ORG}}$ : conteúdo de carbono orgânico

Q: vazão

$\mathrm{k}_{\mathrm{i}}$ : coeficiente de eficiência eletroosmótica

Vol: volume percolado 